\title{
Editorial
}

\section{The global education community}

Education for Information aims to reach and inform readers on educational issues on an international scale, by publishing articles from many different countries and cultures. Each writer has a slightly different view of the world, the perspective being influenced by the writer's locale, and this helps all of us to understand important differences in education needs and practices around the world. What are not often addressed, however, are the issues that arise when an educator from a developed nation wants to help the people of a developing country, either through a teaching sojourn, by providing consultant expertise, by creating educational tools, or by sending materials to the country. Even when the intentions are good and funding is available, the potential problems and pitfalls are many. Among the many questions that could arise:

How should lectures and classroom discussions be adapted for students whose native language is different, or students whose reading and listening comprehension are on a different level?

How can teachers' relate to students who have been taught in a different educational system, and whose ingrained patterns of classroom behavior, study habits, or examinations, are quite different?

How can content that is presented in one medium - whether text-based, oral, electronic, or other - be adapted to another medium of presentation that is more appropriate to the culture and environment of the developing country?

How can foreign consultants adapt their expertise - whether in indexing systems, cataloging and classification, reference services, information technology, or other so that it is relevant to the culture, needs and environment of another country? Many skills and knowledge suitable for a one region cannot be exported without adaptation. For example, a classification system such as UDC that works well in a large library in central Europe may be unusable and inappropriate for a library in Mozambique.

What local culture and customs - including those that are based on age, gender, religion, or social class - must be recognized and respected, even when they are disagreeable to the visitor from the developed country?

How can people in developed countries help those in underdeveloped nations to raise funds or gain outside grants by teaching them to write effective proposals?

How can people in developed countries who collect resources - books, journals, 
or other materials - to ship to a developing country, insure that what is being collected will really meet the needs? What content areas, language, degree of currency, technical level, reading level, formats, or media will be appropriate and usable? What are the storage, dissemination, preservation, and equipment problems in that particular country?

What are the social and economic priorities of the government in a developing country? How can foreigners work within those priorities, while at the same time doing something meaningful to address the information needs of the people?

What territorial and political issues - even military conflicts - stand in the way of building systems to serve the citizens' information needs?

What geographic barriers and climate patterns must be considered in designing information systems and services?

Foreign students who study in developed countries often return to their own country with skills and knowledge that cannot be applied locally. They may be the best and brightest young people of their region, but they often become disheartened, and may even elect not to remain in their country, thus contributing to the "brain drain" problem. How can teachers help these students to adapt what they have learned to their local situation and to encourage and support them after they return home?

This is not an exhaustive list, and none of these questions have easy answers. All of these issues, however, can be addressed by library and information science educators and trainers who live in developing countries and by educators from developed countries who have gained insights from their work and travel in third world countries. They can share their experiences, caution others about pitfalls, suggest solutions, and conduct further research on these issues. I would look forward to reading more on these topics in the pages of this journal.

Trudi Bellardo

Former Associate Editor 